\title{
Alfandary, R. (2019). A Psychoanalytic Study of Lawrence Durrell's The Alexandria Quartet: Exile and Return. London: Routledge. 170 pages. ISBN 978-1-138-35965-9
}

\author{
Wayne E. ARNOLD ${ }^{1}$ (i)
}

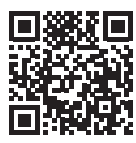

${ }^{1}$ Assoc. Prof., American Literature and Culture, The University of Kitakyushu, Department of Foreign Studies, Fukuoka, Japan

ORCID: W.E.A. 0000-0002-7538-5318

\section{Corresponding author:}

Wayne E. ARNOLD, The University of Kitakyushu, Department of Foreign Studies, Fukuoka, Japan

E-mail: waynearnold55@gmail.com

Submitted: 29.01 .2020

Accepted: 04.02.2020

Citation: Arnold, W. E. (2020). A Psychoanalytic Study of Lawrence Durrell's The Alexandria quartet: Exile and Return [Review of the book $A$ psychoanalytic study of lawrence Durrell's the Alexandria quartet: Exile and return, by R. Alfandary]. Litera, 30(1), 275-281. https://doi.org/10.26650/LITERA2020-0013

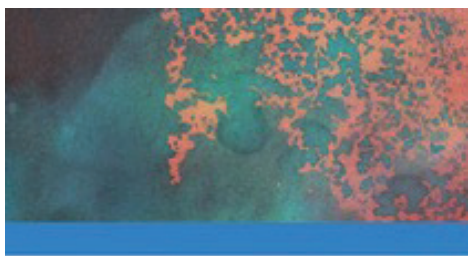

\section{A PSYCHOANALYTIC STUDY OF LAWRENCE DURRELL'S THE ALEXANDRIA QUARTET EXIE AND RETURN}

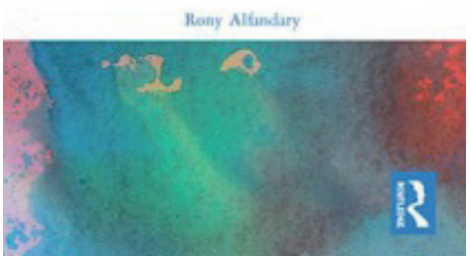

The search for home and a sense of belonging are interwoven themes within Lawrence Durrell's The Alexandria Quartet (1957-59). In this fresh psychoanalytic look into Durrell's most famous series of novels, Rony Alfandary explores how the author deals with the uncanny, or das unheimliche, in his life and writing so as to create an inner literary world, a place that would represent home (p. 138). Alfandary employs a 
close reading of the texts, numerous biographical elements, and a deft application of varying psychoanalytical theories to provide a well-documented evaluation of Durrell and his quartet. While not groundbreaking, this new publication on Durrell is a valuable addition to Durrell studies as well as a professional application of psychoanalysis to literary studies. Spread across an introduction and six chapters, Alfandary moves through each of the four novels (Justine, Balthazar, Mountolive, (lea), focusing on psychoanalytic themes regarding narration, structure, dreams, cities, wandering, and exile. Alfandary is well versed in psychoanalytic literature, and each point is amply supported without straying from the topic in question. As a practicing psychotherapist in Israel, Alfandary applies his practical knowledge and experience to his reading of Durrell's work. Perhaps what makes this work most readable is that the author has purposefully written the text while bearing in mind that many of its readers may not be familiar with Durrell's Alexandria Quartet, thus there is an appropriate mixing of clear explanation of the storyline incorporated with the psychoanalytical approach. The result is an engaging look at Durrell's pursuit of a homeland as expressed through his literature.

Lawrence Durrell was born in Jalandhar, India, in 1912. His parents, both born in India, were closely connected with their Anglo-Indian community, but not associated with the British Army. The traumatic moment in Durrell's childhood, Alfandary argues, occurred when eleven-year old Durrell was required to leave India for England to further his education. Alfandary believes that the rift from the land of his birth and the mother to whom he was closely attached formed in Durrell a sense of the wanderer looking for a homeland. Throughout his life, Durrell moved through and lived in numerous countries around the world. Early in his writing career, Durrell became close friends with Henry Miller and Anaïs Nin. Miller served as a "spiritual father" (p. 126) to Durrell, but their writing and aims in life were certainly distinct. Alfandary is attentive to Durrell's biographical elements, as these directly and indirectly found their way into The Alexandria Quartet. Given specific attention is Durrell's marital issues before and during the composition of these novels. There is also the problem of Durrell's poor treatment of women; judiciously, Alfandary does not shy away from acknowledging the issues of physical and psychological abuse for which Durrell has been accused. These biographical elements are incorporated into the text, providing a psychoanalytical assessment of Durrell's literature that does not overlook the more tragic elements. Durrell struggled with both loneliness (in his search for the place to call home) as well as comradery in his romantic relationships 
until his death in 1990. These subjects form the basis for Alfandary's exploration of the Quartet, and this period of Durrell's literary output is shown to be more biographical than previously understood.

As Alfandary assumes that most of his readers have not read the Quartet, the introduction aims to place the novels in a contemporary context. To do so, Alfandary establishes his modus operandi through the psychoanalysts with whom Durrell most associated: Sigmund Freud (Durrell was well versed in Freud's work from an early age), Otto Rank, Carl Jung, and Georg Groddeck. During the 1930s, Durrell and Miller would discuss via letter their impressions and opinions of psychoanalysis. They also spent seven months together in Paris and one year of exile in Greece in 1940, before the outbreak of World War Two, avidly discussing their theories of life and literature. The two authors fueled each other's interest in psychoanalysis as well as Eastern ideas of Buddhism and Taoism. Self-isolated from specific literary circles, Durrell's search for knowledge and homeland appear in various forms across many of his works. While Durrell may not be as well known today, Alfandary believes that "his life and work epitomize the quest for meaning of the modern man in the Western world in the latter half of the twentieth century" (p. 2). Over the decades, there have been various reasons for Durrell's waning influence. In particular Alfandary assesses Terry Eagleton's unenthusiastic view of Durrell as a "supreme trickster" (p. 9), and the increased disapproval of Durrell after the publication of the diary belonging to his daughter, Sappho Durrell, in which she describes the difficulties of interacting with Durrell as a father.

Drawing attention to Durrell's quest for a home, Chapter 1, "Psychoanalysis, Writing and Exile," begins with a broad overview of the Quartet. Importantly, Alfandary notes that, "it is not my intention to make the picture (the Quartet) fit the frame (theory) but rather to show how psychoanalytic insights helped me to read and understand the Quartet" (p. 13). Biographical as well as fictional elements become tantamount to exploring the narrative form of the text. Additionally, the search for a homeland comes to the forefront of significance concerning the novels; it is a quest, Alfandary suggests, that is situated more internally than externally. One of the big questions brought up in the chapter is whether we should consider Durrell as an exiled writer: exiled from where, Alfandary wonders? Since Durrell frequently moved locations throughout his life, trying to associate him with one specific country becomes troublesome. Durrell's significant relationship to place serves as a pivotal point in the analysis of his texts. Being an exile, however, offers perpetual freedom; 
for example, freedom to write or freedom from one's own culture, according to Jacques Derrida. Examining Durrell's writing while exiled from a place called home encourages Alfandary to conclude that "Durrell's sense of belonging was constituted through his writing" (p. 32). Although the last thirty years of Durrell's life were spent in southern France where he became a naturalized citizen, in his literary world he continued the search for a connection to a homeland.

The narrative structure of the Quartet has received significant critical attention. It may serve as the primary focal point for the breadth of scholarly literature on the series. Chapter 2, "Whose Voice is it Anyway? Narratives and Structure," affords Alfandary the position to argue that Durrell's biographical voice becomes an element of the text. In particular, every novel in the Quartet includes a prefatory note in which Durrell runs through a series of tropes (i.e. characters are all fictional) but within each he alters the wording ever so slightly. The narrative voice of each novel differs to some degree as does the location of the unfolding events, but there is a specific effort by Durrell to keep the reader engaged even after the reading of the novel is over. It is important, Alfandary argues, that the Quartet does not end with death, it is therefore the "renunciation of death" (p. 44) that attracts Alfandary's attention. As the narrative structure changes across the novels, it is up to the reader to determine whom to believe, being encouraged to continue the narrative after reading the final pages. It becomes a plot structure without end, a never-ending story. The construction of the novels contains three layers: narrative voices, complex relationship, and the political situation in Egypt. These layers are superimposed, and the different narrations cohere in "an attempt to make the unconscious conscious" ( $p$. 45). Throughout the utilization of these layers, the varying voices reveal Durrell's perception that the individual involves a multiplicity of internal voices and no single sovereign voice maintains control (p. 48).

With Durrell's interest in Freud it is no surprise that the Quartet contains plenty of dream sequences. Chapter 3, "Dreams and Dreaming," reveals how Durrell "establishes the language of dreams as one of the central pillars of the story," Alfandary argues (p. 56). Dreams structure the novels and also are used to elaborate on themes within the narrative and are crucial to Alfandary's psychoanalytic methodology. Through dreams, Durrell is able to re-represent various incidents in the story, giving multiple voices to the same events. There is then no single version of the true story. The dreams and impression of dreams 
retold create for the reader a multilayered representation of the narrative reality, from which new insight can be determined but never securely ascertained. That dreams may contain historical insight to the past, present, or future events in the novels, while not appearing in a linear plot, is suggestive of Durrell's "conviction that the narrative voice cannot be a single, continuous voice, but rather a multiplicity of voices, to reflect the nature and structure of the human mind" ( $p$. 66). Politics in the Quartet are also linked with the dreams of certain characters. Alfandary notes that political elements within the novels are based on historical events linked to biographical elements from Durrell's extended family; the dream and the political layers emphasize Durrell's incorporation of Freudian ideas. Dreams become an aspiration for the truth: for Durrell, "uncovering of the truth is tantamount to finding one's homeland" (p. 70). Through the inclusion of dreams and the retelling of events, Alfandary surmises that writers (and readers) are able to continually discover themselves anew and learn from previous mistakes through new revelations revealed within the repetition.

Durrell's use of the city of Alexandria, Egypt, has received its varying share of criticism concerning Durrell's intentions for appropriating the city; however, his use of Alexandria has been shown to be more fictional than actual. In Chapter 4, "The Topographic Return to the Mother-City," Alfandary examines the role of the city in the texts, both biographically and literally. From a literary standpoint, Durrell uses the city as the setting for his character's escapades; biographically, the city serves as an important fixture in Durrell's personal letters during the years 1941-45. The presence of the city demonstrates, Alfandary argues, that it is advantageous to view "Alexandria as a central protagonist" in the texts (p. 76). Alexandria is moldable terrain through which Durrell could create his "Heraldic Universe," a universe that is never clearly defined by Durrell but stands as a spiritual symbol of an internal world (p. 81). Durrell's literary city of Alexandria, then, is a "homemade homeland" (p. 81). Chapter 4 outlines Durrell's impression of cityscapes while also explaining how he did not specifically need Alexandria—any city in the West or East might have served Durrell's purpose; nevertheless, after making this point, Alfandary ponders: "Was Alexandria chosen because it is located in the East and unconsciously representing the oriental Other for Durrell, who himself belongs to the Imperial ruling class?" (p. 85). After examining the literary city, Alfandary gives significant text to examining Durrell's actual experiences in the city during these years. These were four crucial years for the construction of The Alexandria Quartet and Alfandary explores Durrell's 
definition of the city as the poetic mother-city, drawing, among others, on the work of Gaston Bachelard and Julia Kristeva.

Chapter 5, "The Secret Wound," is a more detailed examination of Durrell's life. It seems that this chapter might have proven more effective at the beginning of Alfandary's work, but as it is, the chapter delineates some of the more important historical elements in Durrell's biography. In particular, there is heavy emphasis on Durrell's connection with his father and mother, his marriages, and his troubled relationship with his daughter, Sophia. Placing this chapter earlier in the text might have provided the reader a broader perspective of Durrell's life and might have given readers a stronger foundation on which to engage with the Quartet, especially for those unfamiliar with Durrell. Regardless, the chapter highlights important background information in Durrell's life in order to round out Alfandary's psychoanalytical approach.

The short epilogue comprising Chapter 6 reiterates Alfandary's emphasis on literary texts and the biographical connections to their authors. As Alfandary surmises, "this study rests on three conceptual nodal points: the biographicalfictional binary in the interpretation of literary works, the convergence of psychoanalysis and literature, and the concepts of belonging and exile" (p. 138). These three points are incorporated across the five previous chapters, but the central emphasis for Alfandary is that "at the heart of this work lies the poetic space occupied by the mother-city of Alexandria" (p. 140). Durrell's work in The Alexandria Quartet, Alfandary concludes, is a desire to make sense of the life that surrounds us, and in order to do so, for Durrell at least, this effort requires making sense of the alienation surrounding the individual.

Overall, Alfandary's methodology proves valuable for Durrell studies in this specific psychoanalytical publication. More attention might have been given to the heavy influence of Eastern thought on Durrell, especially during the early days of his correspondence with Henry Miller. The most significant detractor from Alfandary's work is the failure to incorporate archival research. Granted, Alfandary had direct correspondence with lan MacNiven, Durrell's authorized biographer, as well as access to Durrell's library of books; however, failing to examine original Durrell materials (at University of California, Los Angles or Southern Illinois University, for example) drastically weakens his overall conclusions. Merely relying on published letters and 
manuscripts leaves Alfandary's observations dependent on the text selections of the editors, and not the original and complete voice of Durrell. While the effort to add archival material may have brought this work beyond its original intent, the psychoanalytical method almost demands that original materials be evaluated and considered superior to edited materials-especially since contemporary research after the archival turn has encouraged the incorporation of fresh materials. The most obvious weakening of Alfandary's arguments appear when he relies solely on the Durrell's published letters to make overarching conclusions, utilizing specifically the Miller-Durrell correspondences, edited by George Wickes (1963) and Ian MacNiven (1988). While archival materials would have benefited this appealing examination of Durrell's Quartet, the thorough reading meshed with detailed biographical elements remain engaging, providing valuable groundwork for future psychoanalytical explorations of Durrell's oeuvre.

\section{Reference}

Alfandary, R. (2019). A Psychoanalytic Study of Lawrence Durrell's The Alexandria Quartet: Exile and Return. London: Routledge. 
